\title{
Cytotoxic hydroanthraquinones from the mangrove-derived fungus Paradictyoarthrinium diffractum BCC 8704
}

\author{
Masahiko Isaka ${ }^{1}$, Panida Chinthanom ${ }^{1}$, Pranee Rachtawee ${ }^{1}$, Kitlada Srichomthong ${ }^{1}$, Prasert Srikitikulchai ${ }^{1}$, \\ Palangpon Kongsaeree ${ }^{2,3}$ and Samran Prabpai ${ }^{2,3}$
}

Two new hydroanthraquinones, paradictyoarthrins A (1) and B (2), were isolated from the mangrove-derived fungus Paradictyoarthrinium diffractum BCC 8704. Structures of the new compounds were elucidated by analyses of the NMR spectroscopic and mass spectrometry data. The absolute configuration of 1 was determined by X-ray crystallography. These compounds exhibited cytotoxic activities.

The Journal of Antibiotics (2015) 68, 334-338; doi:10.1038/ja.2014.153; published online 19 November 2014

\section{INTRODUCTION}

Marine-derived fungi continue to produce structurally unique and diverse secondary metabolites, a considerable number of which display promising biological and pharmacological properties. ${ }^{1}$ Fungi from mangrove habitats are one of the major and prolific sources of important bioactive compounds. ${ }^{1,2}$ Although a number of compounds with significant biological activities have been isolated from these fungal sources, there are still many genera/species that remain chemically unexplored or rarely investigated. As part of our research program on novel bioactive compounds from fungal sources in Thailand, we selected a mangrove-derived fungus Paradictyoarthrinium diffractum, strain BCC 8704, for large scale fermentation and chemical studies. An extract of this strain exhibited cytotoxicity to breast cancer (MCF-7) and small-cell lung cancer (NCI-H187) cells with IC $_{50}$ values of 25 and $20 \mu \mathrm{g} \mathrm{ml}^{-1}$, respectively. To our knowledge, there has been no report of bioactive secondary metabolites from Paradictyoarthrinium or a related genus Dictyoarthrinium. We report here the isolation, structure elucidation and cytotoxic activities of two new hydroanthraquinones, paradictyoarthrins A (1) and B (2), together with three known compounds, preussomerin C (3), ${ }^{3}$ ymf 1029C (4) and altenusin $(5)^{5}$ (Figure 1).

\section{RESULTS AND DISCUSSION}

Paradictyoarthrin A (1) was obtained as a colorless solid, and the molecular formula was established as $\mathrm{C}_{16} \mathrm{H}_{19} \mathrm{ClO}_{8}$, from the protonated quasi-molecular ion peak in the ESI HR-MS. The ${ }^{13} \mathrm{C}$ NMR, DEPT135, and HMQC spectroscopic data indicated the presence of 16 carbons categorized as a conjugated ketone $\left(\delta_{\mathrm{C}} 197.8\right), 4$ quaternary $\mathrm{sp}^{2}$ carbons, $2 \mathrm{sp}^{2}$ methines, 3 oxygenated or chlorinated quaternary carbons $\left(\delta_{\mathrm{C}} 78.8,73.8\right.$ and 70.9$), 3$ oxygenated methines $\left(\delta_{\mathrm{C}} 76.4,70.7\right.$ and 65.8), a methoxy group, a methylene and a methyl group (Table 1). In addition, the ${ }^{1} \mathrm{H}$ NMR spectrum showed the presence of a chelated hydroxyl group $\left(\delta_{\mathrm{H}} 11.70\right)$ and two tertiary and two secondary alcohol functionalities. The structure of the tetrasubstituted benzene ring was deduced from the meta coupling $(J=2.0 \mathrm{~Hz})$ of the two aromatic methine protons $(\mathrm{H}-6 / \mathrm{H}-8)$ and the $\mathrm{HMBC}$ correlations from 5-OH to C-10a, C-5 and C-6, from H-6 to C-10a, C-5, C-7 and C-8, from 7-OCH 3 to C-7, and from $\mathrm{H}-8$ to C-10a, C-6, C-7 and C-8a (Figure 2). The location of the ketone (C-10), connected to C-10a, was suggested by the presence of a chelated phenolic $\mathrm{OH}(5-\mathrm{OH})$. A secondary alcohol carbon (C-9), bonded to C-8a, was assigned by the HMBC correlations from $\mathrm{H}-8$ to this oxygenated carbon (C-9) and the correlation from $\mathrm{H}-9$ to $\mathrm{C}-8$ and $\mathrm{C}-8 \mathrm{a}$. The aliphatic six-membered ring was deduced from the $\mathrm{HMBC}$ correlations as shown in Figure 2. The tricyclic octahydroanthraquinone system was established by the HMBC correlations from $\mathrm{H}-9$ to $\mathrm{C}-1$ and the correlations from $\mathrm{H}-1$ $\left(\delta_{\mathrm{H}} 2.15\right)$ to $\mathrm{C}-9$ and $\mathrm{C}-9 \mathrm{a}$, and a weak ${ }^{4} \mathrm{~J}$ correlation from $\mathrm{H}-1$ to $\mathrm{C}-10$.

The relative configuration of $\mathbf{1}$ was assigned on the basis of the NOESY correlations (Figure 3). An intense NOESY correlation $\mathrm{H}-4 / 9 \mathrm{a}-\mathrm{OH}$ indicated the trans ring junction at $\mathrm{C}-4 \mathrm{a} / \mathrm{C}-9 \mathrm{a}$ and that the terminal cyclohexane adopted a chair conformation wherein $\mathrm{H}-4$ and $9 \mathrm{a}-\mathrm{OH}$ were coplanar $(\alpha$-face). The equatorial $(\beta$-face) orientation of $\mathrm{CH}_{3}-11$ was assigned by the NOESY correlations to $\mathrm{H}_{\mathrm{ax}}-1\left(\delta_{\mathrm{H}} 2.27\right)$, $\mathrm{H}_{\mathrm{eq}}-1\left(\delta_{\mathrm{H}} 2.15\right)$ and $\mathrm{H}-3$. The cross-peak for $2-\mathrm{OH} / \mathrm{H}-3$ indicated a cis relation. $\mathrm{H}-3$ resonated as a narrow multiplet signal, which indicated a

${ }^{1}$ National Center for Genetic Engineering and Biotechnology (BIOTEC), Klong Luang, Pathumthani, Thailand; ${ }^{2}$ Center of Excellence for Innovation in Chemistry, Department of Chemistry, Faculty of Science, Mahidol University, Bangkok, Thailand and ${ }^{3}$ Center for Excellence in Protein Structure and Function, Faculty of Science, Mahidol University, Bangkok, Thailand

Correspondence: Dr M Isaka, National Center for Genetic Engineering and Biotechnology (BIOTEC), 113 Thailand Science Park, Phaholyothin Road, Klong Luang, Pathumthani 12120, Thailand. 
small coupling constant value for $\mathrm{H}-3 / \mathrm{H}-4$. These data were consistent with the equatorial orientation of $\mathrm{H}-3$. An intense NOESY correlation $\mathrm{H}_{\mathrm{ax}}-1 / \mathrm{H}-9$ revealed their coplanar relation ( $\beta$-face) and also suggested a pseudoaxial orientation of H-9. Finally, the structure of 1 was confirmed by X-ray crystallographic analysis (Figure 4). The absolute configuration of this molecule, containing a chlorine atom, was unambiguously determined to be $2 S, 3 S, 4 R, 4 \mathrm{a} R, 9 S$ and $9 \mathrm{a} S$.<smiles>COc1cc(O)c2c(c1)[C@H](O)[C@@]1(O)C[C@](C)(O)[C@@H](O)C(O)[C@]1(Cl)C2=O</smiles>

1

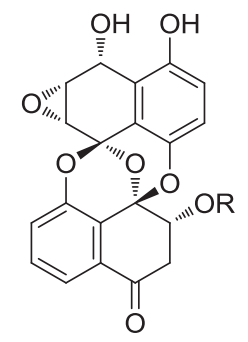

$3 \mathrm{R}=\mathrm{CH}_{3}$ : preussomerin $\mathrm{C}$ $4 \mathrm{R}=\mathrm{H}$ : ymf 1029C<smiles>COc1cc(O)c2c(c1)C(=O)[C@@]13C[C@@](C)(O)C(O)[C@@H](O)[C@]1(C2)C3=O</smiles><smiles>COc1cc(O)c(C(=O)O)c(-c2cc(O)c(O)cc2C)c1</smiles>

5 : altenusin
The molecular formula of paradictyoarthrin B (2) was determined by ESI HR-MS as $\mathrm{C}_{16} \mathrm{H}_{16} \mathrm{O}_{8}$. The ${ }^{1} \mathrm{H}$ and ${ }^{13} \mathrm{C}$ NMR spectra showed some resemblance to $\mathbf{1}$. One of the significant differences was the presence of two conjugated ketones ( $\delta_{\mathrm{C}} 196.1$ and 188.9), which suggested a hexahydroanthraquinone skeleton. Analyses of the HMQC and $\mathrm{HMBC}$ data revealed that the aromatic ring was identical to that of 1 . HMBC correlation from $\mathrm{H}-8$ to one of the ketone groups $\left(\delta_{\mathrm{C}}\right.$ 188.9) indicated the location. The presence of a chelated hydroxyl group $\left(\delta_{\mathrm{H}} 11.68,5-\mathrm{OH}\right)$ suggested that the other ketone $\left(\delta_{\mathrm{C}} 196.1\right)$ should be assigned to C-10. Interpretation of COSY, HMQC and HMBC spectroscopic data revealed that the cyclohexane ring was similar to 1 . However, presence of a 4a,9a-epoxy functionality was the requirement from the molecular formula. The carbon chemical shifts of these quaternary carbons, $\delta_{\mathrm{C}} 62.7(\mathrm{C}-4 \mathrm{a})$ and 66.3 (C-9a), were consistent with the epoxide functionality. The NOESY correlations, $\mathrm{H}_{3}-11 / 3-\mathrm{OH}$ and $\mathrm{H}_{3}-11 / 4-\mathrm{OH}$, suggested the coplanar relations of $\mathrm{CH}_{3}-11,3-\mathrm{OH}$ and $4-\mathrm{OH}$, hence, the relative configuration should be the same as $\mathbf{1}$. These data also suggested that $\mathbf{2}$ undergoes fast conformational exchange between the two half-chair conformers, similar to tetrahydroanthraquinones. ${ }^{6}$ An intense NOESY correlation of one of the methylene protons at $\delta_{\mathrm{H}} 2.30\left(\mathrm{H}_{\beta}-1\right)$ to $\mathrm{H}_{3}$-11 indicated their cis relation. The other methylene proton, $\mathrm{H}_{\alpha}-1$, was significantly downfield shifted $\left(\delta_{\mathrm{H}} 2.87\right)$. These data can be reasonably explained considering the deshielding by the $\mathrm{C}-10$ ketone carbonyl group. ${ }^{7}$ Examinations of the conformations of both $4 a, 9 a-\alpha-$ and $4 a, 9 a-\beta-$ epoxide isomers with molecular models suggested that, in the former configuration, $\mathrm{H}_{\alpha}-1$ lies close to the oxygen atom of the 9-keto-group and more closely in the plane of the carbon-oxygen double bond than $\mathrm{H}_{\beta}-1$ irrespective of the terminal cyclohexane conformation. As an example, stereo structure of only one of the stable conformers of the

Figure 1 Structures of compounds $\mathbf{1 - 5 .}$

Table 1 NMR data for 1 (acetone- $d_{6}, 400 \mathrm{MHz}$ ) and $2\left(\mathrm{CDCl}_{3}, 400 \mathrm{MHz}\right)$

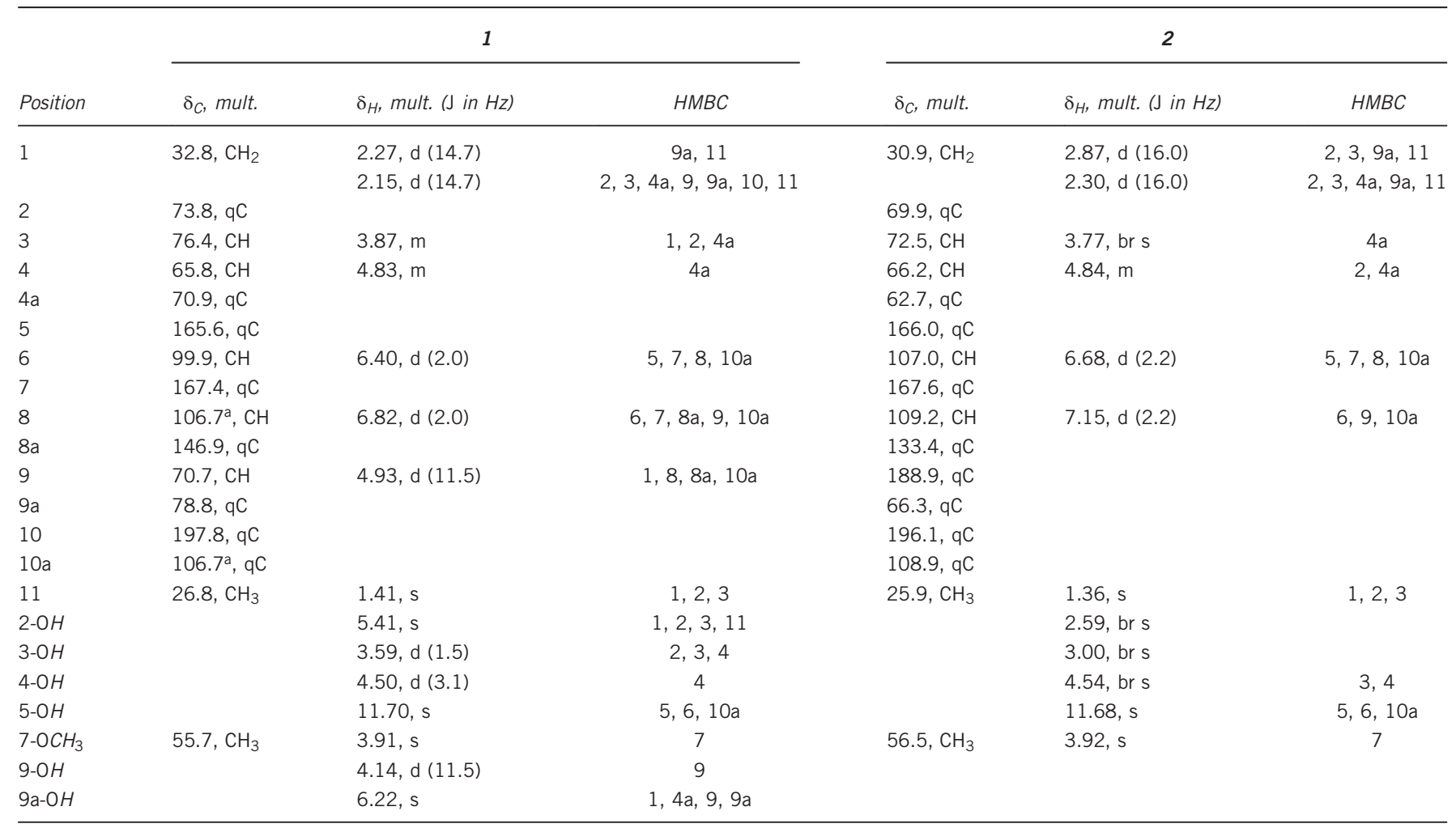

aThe carbon resonances were superimposed. 
$\alpha$-epoxide isomer, energy minimized by MM2 calculation, is shown in Figure 5. This conclusion is consistent with the plausible biosynthetic pathways for the co-metabolite $\mathbf{1}$, wherein the chlorohydrin functionality of the ring junction carbons (C-4a and C-9a) was formed through the cleavage of the $\alpha$-epoxide by the attack of a chloride ion to C-9a from the other side.

A number of hydroanthraquinones have been isolated from fungi. ${ }^{8-10}$ Paradictyoarthrin A (1) is a novel chlorinated derivative. The structure of paradictyoarthrin B (2) is the same as that of

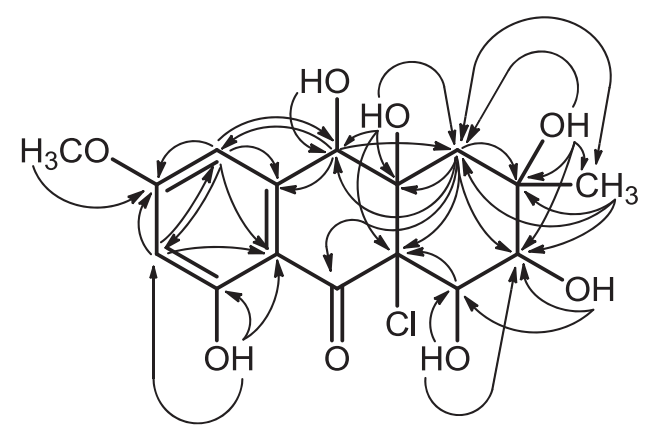

Figure $2 \mathrm{HMBC}$ correlations for 1 .

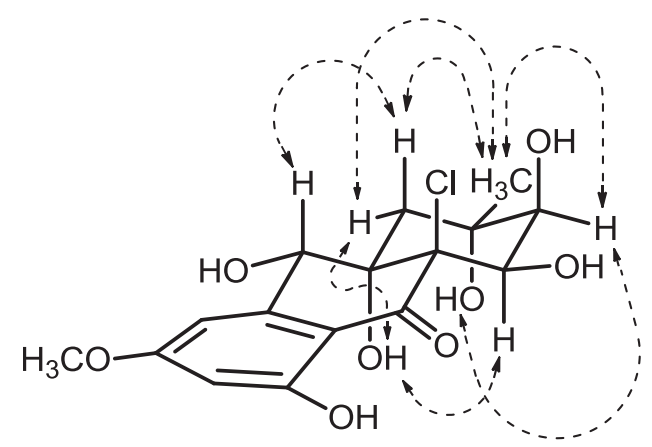

Figure 3 NOESY correlations for 1 . auxarthrol A, which was isolated together with a 4a $\alpha, 9 \mathrm{a} \alpha$-dihydroxy isomer (auxarthrol B) from the fungus Auxarthron umbrinum. ${ }^{11}$ However, comparison of the ${ }^{1} \mathrm{H}$ and ${ }^{13} \mathrm{C}$ NMR spectroscopic data of 2 (in $\mathrm{CDCl}_{3}$ ) with those of the reported data for auxarthrol A (in $\mathrm{CDCl}_{3}$ ) revealed that they are different compounds (Supplementary Table 1). The cis relation of 3-OH and 4-OH in auxarthrol was shown based on an acetonide derivative formation. The paper referred to a 'tentative' assignment of an $\alpha$-epoxide configuration on the basis of the ${ }^{1} \mathrm{H}$ chemical shifts of the acetonide geminal dimethyl groups $\left(\delta_{\mathrm{H}}\right.$ 1.22 and 1.31) with an explanation that one of these was upfield shifted due to the shielding positioning above the quinone double bond. However, the chemical shift differences were too small and the analysis lacked the ${ }^{1} \mathrm{H}$ assignment of the nonequivalent geminal dimethyl groups. Furthermore, the acetonide should prefer a conformation that envelop of the acetone-derived unit flipped to the less hindered $\alpha$-side. Our own examination of the acetonide derivative with molecular models also suggested that such shielding effect was unlikely. The description was also lacking a logical explanation of the relative configuration of $\mathrm{C}-2$. Accordingly, some additional experimental data should be required to establish the relative configurations of auxarthrols A and B.

All isolated compounds (1-5) were tested for cytotoxic activities against cancer cell-lines, KB (oral cavity carcinoma), MCF-7 (breast

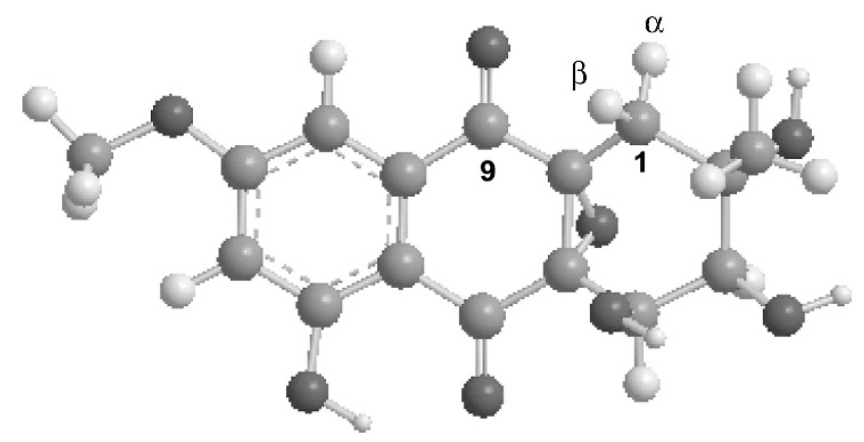

Figure $\mathbf{5}$ One of the stable conformers of $\mathbf{2}$.

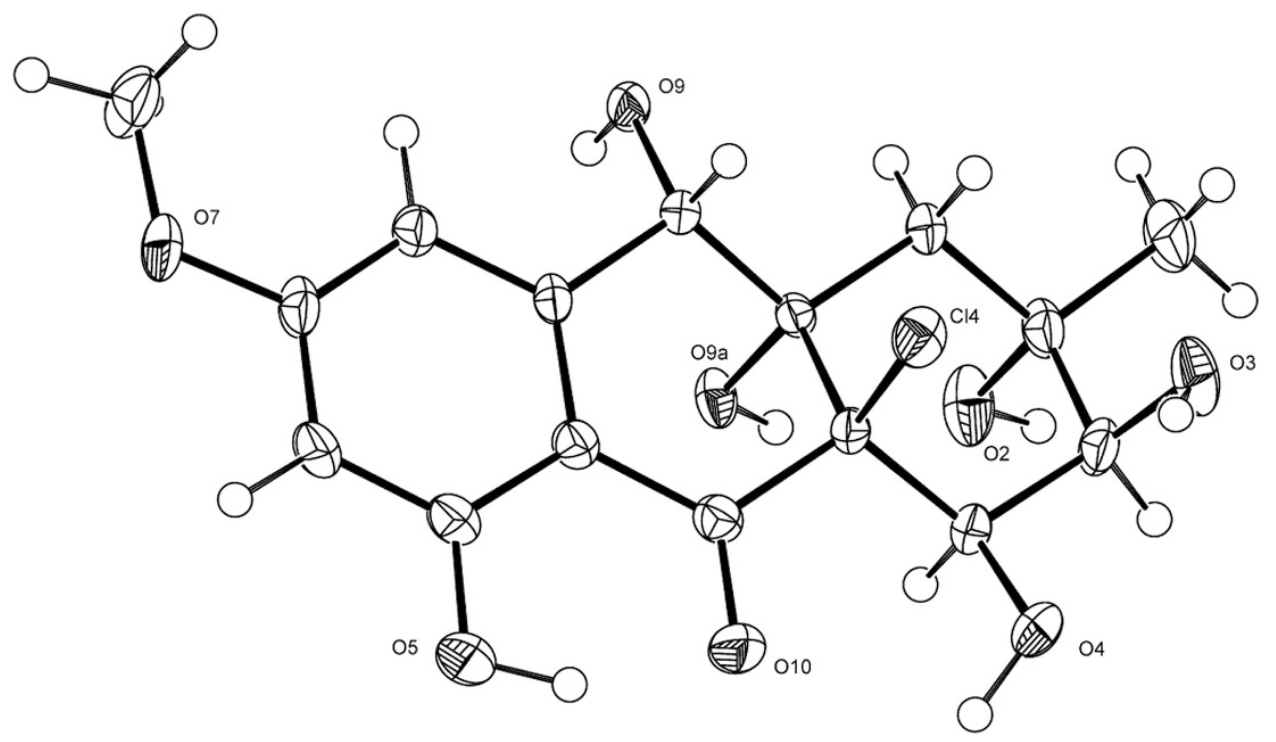

Figure 4 Crystal structure of 1. 
Table 2 Cytotoxic activities of compounds $1-5\left(\mathrm{IC}_{50}, \mu \mathrm{g} \mathrm{ml}-1\right)$

\begin{tabular}{lcccc}
\hline Compound & KB & MCF-7 & NCl-H187 & Vero \\
\hline $\mathbf{1}$ & 26 & 24 & 23 & 31 \\
$\mathbf{2}$ & 3.1 & 3.8 & 9.5 & 5.6 \\
$\mathbf{3}$ & $>50$ & $>50$ & 21 & 36 \\
$\mathbf{4}$ & 38 & 34 & 5.0 & 13 \\
$\mathbf{5}$ & 14 & 9.3 & $>50$ & 12 \\
Doxorubicin hydrochloride $^{\mathrm{a}}$ & 0.57 & 9.5 & 0.076 & $-\mathrm{b}$ \\
Ellipticine $^{\mathrm{a}}$ & 0.94 & $\mathbf{C}^{\mathrm{b}}$ & 0.50 & 1.8 \\
\hline
\end{tabular}

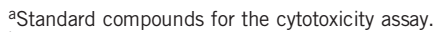

bNot tested.

cancer), and NCI-H187 (small-cell lung cancer), and noncancerous Vero cells (African green monkey kidney fibroblasts). Paradictyoarthrin B (2) exhibited moderate cytotoxicity to all tested cell-lines, whereas paradictyoarthrin A (1) showed weaker activity (Table 2). The spirodioxynaphthalenes of the preussomerin family, including $\mathbf{3}$ and $\mathbf{4}$, have been shown to exhibit broad range of biological activities. ${ }^{12}$ In our assays, ymf 1029C (4) showed relatively stronger cytotoxicity to NCI-H187 cells than other cell-lines.

\section{METHODS}

\section{General experimental procedures}

Melting points were measured with an IA9100 digital melting point apparatus (Electrothermal, Essex, UK). Optical rotations were measured with a P-1030 digital polarimeter (JASCO, Tokyo, Japan). UV spectra were recorded on a Cintra 404 spectrophotometer (GBC Scientific Equipment, Braeside, VIC, Australia). FTIR spectra were taken on an ALPHA spectrometer (Bruker, Bremen, Germany). NMR spectra were recorded on a DRX400 spectrometer (Bruker). ESI-TOF mass spectra were measured with a micrOTOF mass spectrometer (Bruker).

\section{Fungal material}

The fungus used in this study was isolated from a mangrove wood in Laem Son National Park, Ranong Province, Thailand. This fungus was deposited in the BIOTEC Culture Collection (BCC) on 3 March 2001 as BCC 8704. On the basis of the morphological characteristics and the sequence data of the internal transcribed spacer (ITS) ribosomal DNA (GenBank registration number: KJ906508), the strain was identified as Paradictyoarthrinium diffractum.

\section{Fermentation, extraction and isolation}

The fungus BCC 8704 was maintained on potato dextrose agar at $25^{\circ} \mathrm{C}$. The agar was cut into small plugs and inoculated into $3 \times 250 \mathrm{ml}$ Erlenmeyer flasks containing $25 \mathrm{ml}$ of potato dextrose broth (potato starch $4.0 \mathrm{gl}^{-1}$, dextrose $20.0 \mathrm{gl}^{-1}$ ). After incubation at $25^{\circ} \mathrm{C}$ for 11 days on a rotary shaker (200 r.p.m.), each primary culture was transferred into a 11 Erlenmeyer flask containing $250 \mathrm{ml}$ of the same liquid medium (potato dextrose broth), and incubated at $25^{\circ} \mathrm{C}$ for 11 days on a rotary shaker ( 200 r.p.m.). These secondary cultures were pooled and each $25 \mathrm{ml}$ portion was transferred into $28 \times 11$ Erlenmeyer flasks containing $250 \mathrm{ml}$ of potato dextrose broth, and final fermentation was carried out at $25^{\circ} \mathrm{C}$ for 106 days under static conditions. The culture was filtered to separate broth (filtrate) and mycelia (residue). The filtrate was extracted with EtOAc $(2 \times 101)$, and the combined organic layer was concentrated under reduced pressure to obtain a dark brown gum $(3.19 \mathrm{~g}$, broth extract). The wet mycelia were macerated in $\mathrm{MeOH}$ (1.5 l, room temperature, 2 days $)$ and filtered. Hexanes $(400 \mathrm{ml})$ and $\mathrm{H}_{2} \mathrm{O}(400 \mathrm{ml})$ were added to the filtrate, and the layers were separated. The aqueous $\mathrm{MeOH}$ (bottom) layer was partially concentrated by evaporation, and the residual aqueous solution was diluted with $\mathrm{H}_{2} \mathrm{O}(100 \mathrm{ml})$ and then extracted with EtOAc $(500 \mathrm{ml})$. The EtOAc solution was concentrated under reduced pressure to obtain a brown gum ( $1.37 \mathrm{~g}$, mycelial extract). The broth extract was fractionated by column chromatography on Sephadex LH-20 $(3.7 \times 60 \mathrm{~cm}$, $\mathrm{MeOH})$ to obtain four pooled fractions. Fraction 2 (100 mg) was further purified by column chromatography on silica gel $\left(3.0 \times 15 \mathrm{~cm}, \mathrm{MeOH} / \mathrm{CH}_{2} \mathrm{Cl}_{2}\right)$ and preparative HPLC (Phenomenex Luna 10u C18(2) 100A, $21.2 \times 250 \mathrm{~mm}$, $10 \mu \mathrm{m}$, Phenomenex, Torrance, CA, USA; $\mathrm{MeCN} / \mathrm{H}_{2} \mathrm{O}=35: 65$, flow rate $\left.8 \mathrm{ml} \mathrm{min}^{-1}\right)$ to furnish $1(13 \mathrm{mg})$. Fraction $3(1.56 \mathrm{~g})$ was further fractionated by column chromatography on silica gel $\left(3.3 \times 15 \mathrm{~cm}, \mathrm{MeOH} / \mathrm{CH}_{2} \mathrm{Cl}_{2}\right)$ and the eluted fractions were purified by preparative HPLC $\left(\mathrm{MeCN} / \mathrm{H}_{2} \mathrm{O}=35: 65\right)$ to furnish 1 (20 mg), 2 (18 mg) and $\mathbf{5}(198 \mathrm{mg})$. The mycelial extract was fractionated by column chromatography on silica gel $\left(\mathrm{MeOH} / \mathrm{CH}_{2} \mathrm{Cl}_{2}\right)$ and preparative HPLC $\left(\mathrm{MeCN} / \mathrm{H}_{2} \mathrm{O}\right)$ to obtain $3(18 \mathrm{mg}), 4(6 \mathrm{mg})$ and $5(80 \mathrm{mg})$.

Paradictyoarthrin A (1): yellow solid; m.p. $226-228^{\circ} \mathrm{C} ;[\alpha]_{\mathrm{D}}^{28}+32(c 0.115$, $\mathrm{MeOH}) ; \mathrm{UV}(\mathrm{MeOH}) \lambda_{\max }(\log \varepsilon) 218$ (4.07), $236 \mathrm{sh}$ (3.86), 291 (4.10), $327 \mathrm{sh}$ (3.91) nm; IR (ATR) $\nu_{\max } 3449,3365,1738,1623,1365$ and $1205 \mathrm{~cm}^{-1}$; ${ }^{1} \mathrm{H}$ NMR $\left(400 \mathrm{MHz}\right.$, acetone- $\left.d_{6}\right)$ and ${ }^{13} \mathrm{C}$ NMR $\left(100 \mathrm{MHz}\right.$, acetone- $\left.d_{6}\right)$ data, see Table 1; HRMS (ESI-TOF, positive) $\mathrm{m} / z 375.0848[\mathrm{M}+\mathrm{H}]^{+}$(calculated for $\left.\mathrm{C}_{16} \mathrm{H}_{20} \mathrm{ClO}_{8}, 375.0841\right)$.

Paradictyoarthrin B (2): pale brown solid; mp $126-128^{\circ} \mathrm{C} ;[\alpha]_{D}^{28}+151$ (c 0.085, MeOH); UV (MeOH) $\lambda_{\max }(\log \varepsilon) 211$ (4.10), 248 (4.24), 307 (3.83), 362 (3.90) nm; IR (ATR) $\nu_{\max } 3449,1738,1699,1636,1614,1382,1304$ and $1206 \mathrm{~cm}^{-1}$; ${ }^{1} \mathrm{H}$ NMR $\left(400 \mathrm{MHz}, \mathrm{CDCl}_{3}\right)$ and ${ }^{13} \mathrm{C} \mathrm{NMR}(100 \mathrm{MHz}$, $\mathrm{CDCl}_{3}$ ) data, see Table 1; HRMS (ESI-TOF, positive) $\mathrm{m} / z 337.0919[\mathrm{M}+\mathrm{H}]^{+}$ (calculated for $\mathrm{C}_{16} \mathrm{H}_{17} \mathrm{O}_{8}, 337.0918$ ).

\section{X-ray crystallographic analysis of 1}

$\mathrm{C}_{16} \mathrm{H}_{19} \mathrm{ClO}_{8}, \mathrm{MW}=374.78$, monoclinic, dimensions: $0.40 \times 0.20 \times 0.10 \mathrm{~mm}^{3}$, $D=1.510 \mathrm{~g} \mathrm{~cm}^{-3}$, space group P2 $, \quad Z=2, a=7.5490(2), b=9.5140(2)$, $c=11.8190(3) \AA, \beta=103.861(1) V=824.14(4) \AA^{3}$, reflections collected/unique: $3504 / 2408$, number of observations $[>2 \sigma(I)] 2329$, final $R$ indices $[I>2 \sigma(I)]$ : $R_{1}=0.0389, \mathrm{w} R_{2}=0.1231$. Flack parameter $=-0.03(4)$. X-ray diffraction data were measured on a Bruker-Nonius kappaCCD diffractometer with graphite monochromated MoK $\alpha$ radiation $(\lambda=0.71073 \AA)$ at $298(2) \mathrm{K}$. The structure was solved by direct methods using SIR $97,{ }^{13}$ and refined with full-matrix leastsquares calculations on $F^{2}$ using SHELXL-97. ${ }^{14}$ Crystallographic data have been deposited at the Cambridge Crystallographic Data Centre under the reference numbers CCDC 1019397. Copies of the data can be obtained, free of charge, on application to the Director, CCDC, 12 Union Road, Cambridge, CB2 1EZ, UK (e-mail: deposit@ccdc.cam.ac.uk).

\section{Biological assays}

Cytotoxic activities against human cancer cell-lines, KB (oral cavity cancer), MCF-7 (breast cancer) and NCI-H187 (small-cell lung cancer) cells, were evaluated using the resazurin microplate assay. ${ }^{15}$ Cytotoxicity to Vero cells (African green monkey kidney fibroblasts) was performed using the green fluorescent protein microplate assay. ${ }^{16}$

\section{ACKNOWLEDGEMENTS}

Financial support from the National Center for Genetic Engineering and Biotechnology (BIOTEC) is gratefully acknowledged.

1 Rateb, M. E. \& Ebel, R. Secondary metabolites of fungi from marine habitats. Nat. Prod. Rep. 28, 290-344 (2011).

2 Blunt, J. W., Copp, B. R., Keyzers, R. A. \& Munro, M. H. G. Marine natural products. Nat. Prod. Rep. 31, 160-258 (2014).

3 Weber, H. A. \& Gloer, J. B. The preussomerins: novel antifungal metabolites from the coprophilous fungus Preussia isomera Cain. J. Org. Chem. 56, 4355-4360 (1991).

4 Dong, J. Y. et al. Ymf 1029A-E, preussomerin analogues from fresh-water-derived fungus YMF 1.01029. J. Nat. Prod. 71, 952-956 (2008).

5 Coombe, R. G., Jacobs, J. J. \& Watson, T. R. Metabolites of some Alternaria species. The structures of altenusin and dehydroaltenusin. Aust. J. Chem. 23 2343-2351 (1970).

6 Ondeyka, J. et al. Isolation, structure elucidation, and biological activity of altersolanol P using Staphylococcus aureus fitness test based genome-wide screening. J. Nat. Prod. 77, 497-502 (2014).

7 Jackman, L. M. \& Sternhell, S. Applications of Nuclear Magnetic Resonance Spectroscopy in Organic Chemistry 2nd edn, 88-92 (Pergamon Press: Oxford, 1969).

8 Zheng, C.-G. et al. Bioactive hydroanthraquinones and anthraquinone dimers from a soft coral-derived Alternaria sp. fungus. J. Nat. Prod. 75, 189-197 (2012). 
$9 \mathrm{Xu}$, J. et al. Tetrahydrobostrycin and 1-deoxytetrahydrobostrycin, two new hexahydroanthraquinone dimers, from a marine-derived fungus Aspergillus sp. J. Antibiot. 61, 415-419 (2008).

10 Yang, K.-L. et al. Antibacterial anthraquinone derivatives from a sea anemone-derived fungus Nigrospora sp. J. Nat. Prod. 75, 935-941 (2012).

11 Alvi, K. A. \& Rabenstein, J. Auxarthrol A and auxarthrol B: two new tetrahydroanthraquinones from Auxarthron umbrinum. J. Ind. Microbiol. Biotechnol. 31 $11-15$ (2004).

12 Cai, Y.-S., Guo, Y.-W. \& Krohn, K. Structure, bioactivities, biosynthetic relationships and chemical synthesis of the spirodioxynaphthalenes. Nat. Prod. Rep. 27, 1840-1870 (2010).
13 Altomare, A. et al. SIR97: A new tool for crystal structure determination and refinement. J. Appl. Crystallogr. 32, 115-119 (1999).

14 Sheldrick G. M. A short history of SHELX. Acta Crystallogr. A 64, 112-122 (2008)

15 O'Brien, J., Wilson, I., Orton, T. \& Pognan, F. Investigation of the Alamar Blue (resazurin) fluorescent dye for the mammalian cell cytotoxicity. Eur. J. Biochem. 267, 5421-5426 (2000).

16 Changsen, C., Franzblau, S. G. \& Palittapongarnpim, P. Improved green fluorescent protein reporter gene-based microplate screening for antituberculosis compounds by utilizing an acetamidase promoter. Antimicrob. Agents Chemother. 47, 3682-3687 (2003).

Supplementary Information accompanies the paper on The Journal of Antibiotics website (http://www.nature.com/ja) 